\title{
Michael Toman*
}

\section{The need for multiple types of information to inform climate change assessment}

\begin{abstract}
Many critics of economic analysis of climate change impacts and response options claim that information is needed on ecosystem characteristics as well as on economic values to fully inform decisions about how climate change affects human well-being. Information on the irreversibility of impacts also is important, critics argue, because it relates to how society evaluates implications for intergenerational equity. In addition, because climate change is subject to a large degree of Knightian uncertainty, it is useful to understand both the information available for assessing climate change risks, and how individuals themselves perceive and evaluate risks. The paper discusses rationales for using these types of information as important complements to benefit-cost analysis for evaluating climate change risks and responses. Ideally such information could be available in a "dashboard" for decision makers assessing social and economic impacts, although limits on currently available information are a significant barrier to using that approach.
\end{abstract}

Keywords: benefit-cost analysis; climate change; ecosystem valuation; intergenerational equity; safe minimum standard; sustainable development; uncertainty.

\section{Introduction}

For the Second Assessment Report of the Intergovernmental Panel on Climate Change (IPCC), David Pearce led a team that investigated the economic costs of climate change (Pearce et al., 1996). Among the impacts assessed was the threat of increased mortality, for example, from increased occurrence of tropical diseases and more intense heat waves in locations where the poor did not have much access to air conditioning. Carefully documenting every assumption and calculation, Pearce and his co-authors determined a range of estimates for the economic cost of increased mortality risk. The upper bound used estimates from work in

*Corresponding author: Michael Toman, Lead Economist, Development Research Group, World Bank, 1818 H St., NW, Washington, DC 20433, USA, e-mail: mtoman@worldbank.org 
Organisation for Economic Co-operation and Development (OECD) countries on the value of statistical life, and the lower bound used that value scaled by relative incomes, assuming a unit income elasticity for the statistical life valuation. The authors pointed out that there were good reasons to think that the elasticity would be $<1$, putting the value somewhere inside the range. The authors were vilified by a number of critics who accused them, among other things, of saying that the life of a poor person is worth only a fraction of a life of someone in the OECD. ${ }^{1}$

This story illustrates both the importance of doing serious assessment of costs and benefits of climate change, and the difficulty one faces in carrying out such assessment. The criticism of the economic valuation work in the Second Assessment Report (which has had a lingering effect on subsequent IPCC assessments) was not the result of ignorance. It reflects a deep disagreement with the assumptions - and even the framing of issues - that go into the economic calculus.

A great deal of the benefit-cost analysis (BCA) carried out for climate change makes use in one way or another of "integrated assessment" models (IAMs) (for further discussion of these models see the paper by Weyant (2014). A modeling approach is unavoidable given that we have little observational information for constructing a climate change damage function, especially one that would describe the future impacts of current emissions, and only somewhat better information for constructing an emissions mitigation cost function given uncertainties about future energy and other technologies. Like any model, IAMs are built on a set of parametric and structural assumptions, in this case for representing both the future evolution of the climate system and the future evolution of the economic system (and interactions between them).

The robustness of IAMs for assessing costs of climate change and benefits from response options is a matter of ongoing debate. What can be said, however, is that IAMs provide the capacity for a variety of important "if-then" policy impact experiments, and anything that can improve the scope and accuracy of information in the IAMs is beneficial. Especially high priority are efforts that can reduce uncertainty about probabilities related to climate change, and efforts that can increase the scope of what can be captured in the representation of economic damages from climate change (Gerst, Howarth, \& Borsuk, 2010; Yohe, 2009).

Some critics of BCA applied to climate change have suggested that even with such improvements, economic analysis of climate change's costs and benefits is

1 This was reported at the time in, e.g., Masood (1995). Pearce and his colleagues stood by the scientific integrity of what they had done, and Pearce in particular protested modification of the basic conclusions in later summary documents. For further explanation of the approach taken, see Fankhauser, Tol, \& Pearce $(1997,1998)$. 
not useful and should not be performed. However, measures of economic costs and benefits inevitably, and appropriately, play a significant role in public policy evaluation and resource allocation for climate change (Yohe, 2009). Done well, economic analysis can provide an organized and transparent approach to assessing climate change risks and response options. ${ }^{2}$ This can be useful in the face of high uncertainties surrounding climate change and the cacophony of different philosophical and political perspectives held about it.

Nevertheless, there are limits to what economic analysis can accomplish in informing climate change debates. Yohe (2009) expresses one important perspective on this issue by noting the need for a "risk management approach" to complement conventional BCA, with its focus on expected net benefits (or certainty-equivalent results from a small number of scenarios). He cites language from the Fourth Assessment Report of the Intergovernmental Panel on Climate Change: "Responding to climate change involves an iterative risk management process that includes both adaptation and mitigation, and takes into account climate change damages, co-benefits, sustainability, equity and attitudes to risk" (see IPCC, 2007, p. 22). ${ }^{3}$

This quotation emphasizes a very inclusive approach toward measurement of benefits and costs; the importance of distributional issues; and an approach to incorporating (quantifiable) uncertainty that takes into account the overall nature of the risk distribution, not just central tendencies. It also highlights the importance of learning about risks and costs, and incorporating new information when analyzing them. Given the nature of climate change, these are very important considerations for providing a clearer and comprehensive picture to decision

2 US Office of Management and Budget (OMB 2003) guidance for regulatory impact analysis states (p. 2): "Regulatory analysis is a tool regulatory agencies use to anticipate and evaluate the likely consequences of rules. It provides a formal way of organizing the evidence on the key effects - good and bad - of the various alternatives that should be considered in developing regulations. The motivation is to (1) learn if the benefits of an action are likely to justify the costs or (2) discover which of various possible alternatives would be the most cost-effective."

3 As noted by an anonymous referee, much of the debate over the lessons to be drawn from IAMs has been focused on the strengths and weaknesses of the standard Hicks-Kaldor criterion in cost-benefit analysis, that a project is good if benefits exceed costs in the aggregate and benefits to winners are sufficient to compensate losers. As part of that, criticisms of conventional approaches to discounting as marginalizing future generations recalls arguments from classical utilitarianism. However, the relative lack of attention to distributional issues in many cost-benefit analyses overlooks the possibility that a major change in distribution from climate change or from policy responses to it could leave a society concerned with distributional equity worse off, even if the Hicks-Kaldor criterion was satisfied [see Sussman, Weaver and Grambsch (2014)]. No less important, much less attention has been paid to the limitations in how climate change risks and damages are typically described in IAMs. 
makers of what is at stake. At the same time, the importance of incorporating these considerations is underscored in best-practice documents such as OMB (2003), and so they are consistent with high-quality BCA (although in practice they may not get addressed as one would like).

This paper focuses on the needs for other information to complement the application of BCA to climate change. One concern involves reservations with respect to addressing the risks of climate change and the impacts of response policies with a small number of economic summary statistics, even when the statistics are transparently calculated and presented according to best practice. This concern arises especially in the context of addressing the systemic effect of climate change on ecosystems, and it argues for including measures of changes in ecosystem characteristics from climate change, not just measures of economic values of service flows provided by ecosystems.

Two additional concerns reflect the nature of climate change as involving potentially quite large and irreversible impacts. This has implications for how society evaluates moral aspects of climate change risks and responses, in particular the implications for intergenerational equity. In addition, the nature of these impacts is subject to a large degree of Knightian uncertainty (Knight, 1921), in contrast to uncertainty that can be more readily quantified statistically (i.e., statistical risk). Both of these considerations have implications for how individuals perceive and evaluate climate change risks, which indicate in turn the usefulness of having more information about what goes into shaping those perceptions.

The next three sections of this paper develop these strands of argument for evaluating climate change risks and responses. Section 5 summarizes the implications for providing information that complements findings from BCA.

\section{Differences in ecological valuation metrics}

Guidance for best-practice BCA prescribes that when an important impact of a prospective policy cannot be monetized, it should be otherwise quantified to the extent practicable. Similarly, distributional considerations are to be quantified and described separately from the analysis of overall costs and benefits. ${ }^{4}$ Nevertheless, the usefulness of applying BCA to climate change (and other larger-scale

\footnotetext{
4 See OMB (2003), pp. 2, 14, and 18, and U.S. EPA (2014), Sections 7.5 and 11.1, for examples of such guidance in the context of regulatory policy analysis. The EPA guidance in fact describes how economic and non-economic information can be brought together in an organized way to inform users of the regulatory analysis. Hanley and Barbier (2009) provide further insight into best practices for environmental BCA.
} 
ecosystem changes) has been contested on two grounds related to metrics for assessing values associated with ecosystems. ${ }^{5}$

One set of criticisms, from behavioral economics, argues that actual behavior of individuals departs from the predictions of a standard economic model of maximizing individualistic well-being. In addition to issues related to how individuals perceive and respond to uncertainty, the topic of Section 4 below, several other issues related to measurement of benefits and costs have been pointed out by various authors. Perhaps the most familiar is that individuals seem to discount the longer-term future less extensively than is implied by the standard model of exponential discounting. This means that longer-term costs of climate change and longer-term benefits of response options count more than in standard BCA. ${ }^{6}$ The behavioral economics literature also indicates that people exhibit a regard for others that motivates self-sacrifices beyond what a standard preference ordering with altruism would predict (Gowdy \& Manner, 2010; Gsottbauer \& Bergh, 2011).

Another argument is based on loss aversion: individuals value reductions in income from a particular reference point more than equal increases. This would tend to increase the cost (in utility terms) of bearing nearer-term costs for longerterm gains. The same can be said of the effects of inertia and the use of heuristics in evaluating a change from the status quo (Hammitt, 2013). Preferences are not a once-for-all given, but evolve with experience (Gowdy, 2004). Perceived fairness is itself an influence on well-being, according to the behavioral literature, so evaluation of climate change risks and responses needs to account for people's feelings about the justness of an outcome and the fairness of the procedures leading to it (Faucheux \& Froger, 1995).

In principle at least, these concerns could be addressed by modifying how a BCA is carried out. Another set of criticisms, from philosophy and systems ecology, argues that the concepts of monetization and net benefit calculation themselves

5 As Neumann and Strzepek (2014) show in their paper in this issue, the impacts of climate change are significant and varied. They include impacts on productivity of agricultural lands; changes in species range and incidence of pests; and coastal flooding, among others. These can be evaluated at a variety of spatial scales. At a local scale, one can assess the impact on crop yields or vulnerability of specific coastal wetlands. At a broader scale, one can assess, for example, the impacts on productivity of a country's entire agricultural landscape, and the consequences for its social structure as well as economy. As discussed below, the ability to assess these larger-scale impacts is a key element in philosophical as well as methodological criticisms of applying BCA to climate change.

6 See, e.g., Hammitt (2013). There is increasing conceptual work in support of the argument that the socially optimal discount rate applied to climate change should decline over time, even without resorting to intergenerational equity or behavioral arguments (Gowdy, 2004). 
are inherently limited in their capacity to provide information sufficient for evaluation of the impacts of climate change on ecosystems, and the benefits from policy responses to those impacts. Norton (2005) argues that environmental problems are inherently "messy," or "wicked" (see also Batie, 2008), in the sense of not fitting comfortably into any one set of assumptions and value judgments - be it the assumptions and judgments used by economists to determine what is important to study, or principles of distributive justice or inherent rights. The difficulty is especially acute in addressing a problem such as climate change, since the relevant impacts operate across many different spatial scales and associated temporal scales over which change occurs. From this perspective, Norton questions the conceptual and practical soundness of any "monistic" or "reductionist" approach that seeks to impose one analytical framework leading to a single metric of value. Both ecosystems and people are more complicated than that.

The concern about how climate change can affect ecosystems in complex and large-scale ways is hardly restricted to environmental philosophy. The latest (fifth) climate change assessment by the IPCC provides evidence for serious concern about the potential impacts of unrestricted anthropogenic climate change. Even leaving aside the risks of very large-scale catastrophic events, climate change poses threats ranging from impacts on unique ecosystems to impacts on the overall economy that grow more severe as the change in global average temperature becomes greater. Even before serious effects are widely felt, the IPCC concludes, they will be felt in lower-income and more vulnerable economies. ${ }^{7}$

Norton and Noonan (2007) further articulate the view that ultimately, the whole concept of an ecosystem used to organize information about the natural world and human impacts on it is not just a measurable scientific construct. Instead, it "...rests on metaphors... [that] connect our values and emotions with our choice of models” for evaluation. ${ }^{8}$ Norton and Noonan argue that the types of human values associated with longer-term and larger-scale functioning of ecosystems that are suggested by this metaphor are not capable of being adequately captured in an economic analysis, even one that includes existence values. Toman (1994, p. 405) classified this position as a kind of "ecological organicism ...[it] is not entirely individualistic; it also encompasses concerns for ecological systems and the human species as a whole."9

7 See IPCC (2014), p. 13.

8 To illustrate this point, the authors quote Aldo Leopold, the American preservationist and philosopher, who said in his essay "Thinking Like a Mountain" that “...only the mountain has lived long enough to listen objectively to the howl of the wolf" (Leopold, 1949, p. 129).

9 For a somewhat contrary view of what can be incorporated in economic analysis of large-scale risks, see Barbier (2011). 
Nelson (2013) goes even further in emphasizing the connection of values to emotions. She argues that feelings about what is right or necessary (e.g., empathy or shame) are as important or more important than moral principles, let alone preferences, in explaining what people actually do. What drives choices then becomes a much more complicated set of motivations than is envisaged in the standard revealed-preference individual economic model underlying BCA including issues related to altruism, community, loyalty, self-image, and importantly, the conditioning of past experiences.

What do these observations on the limits of standard economic metrics tell us about what is important to measure for assessing climate change? Norton and Noonan (2007) argue that this question cannot be answered until individuals with different values and perspectives begin to have a common understanding of the problem. However, this begs the question of how such a shared understanding can be gained in practice (see Section 5 below). At the very least, it would seem to be important to provide information on the vulnerability of different ecosystems and their functions to climate change, and the perceptions that people hold about such vulnerabilities - in addition to measures of the economic costs of climate change.

\section{Irreversibility, intergenerational equity, and assessment of climate change}

Toman (1994) argues that the larger the scale and the more irreversible the impacts of ecosystem changes - as would be the case with unconstrained growth in greenhouse gas emissions - the more limited is the ability of economic BCA to adequately inform social choices. There are two reasons for this. One is that larger and more irreversible changes can call into question the common economic assumption of significant substitutability between "natural capital" and other forms of societal wealth, which at least in principle would make possible continued improvements in human well-being even with rising climate change damages. The limit on substitutability can reflect both the difficulty for individuals to evaluate losses of unique environmental and cultural assets, and the challenge of overcoming negative impacts on economic activity from seriously compromised ecosystem processes that are fundamental for economic function and life itself. When substitution is more limited, shadow prices are harder to define meaningfully. This compounds the problem already noted regarding the adequacy of economic valuation statistics to reflect concerns regarding largescale threats to the environment (Norton \& Toman, 1997). 
The other reason is that larger and more irreversible ecosystem changes of the type expected from global climate change are likely to have important implications for intergenerational equity, about which standard BCA is silent. Purely economic motivations tend to have a fairly short-term orientation, even if individuals' preferences incorporate a degree of altruism. Equity-based considerations regarding the risks of climate change or the benefits of response options would be grounded in moral sentiments regarding the importance of maintaining a wide range of opportunities for future generations in general.

Even with such a motive, however, it may not even be possible to provide an intergenerational bequest with comparable opportunities to the present, unless certain key elements of natural capital are safeguarded from the adverse impacts of climate change. Howarth $(1997,2007)$ provides a deeply probing analysis of how concepts of the rights of and responsibilities to future generations, along with ethics of stewardship held by the current generation, can shape an approach to "sustainability as opportunity." His analysis leads to recommendations for incorporating specific bequests of natural capital (those related to underlying life-supporting ecosystem functions in particular) such that there is a meaningful possibility for future generations to enjoy undiminished (or increased) opportunities. In practice, there continues to be empirical debate among economists and ecologists about what parts of the natural endowment should be regarded as “critical natural capital” (see Ekins, Simon, Deutsch, Folke, \& De Groot, 2003 for one approach).

In light of the challenges discussed above, some analysts have looked for evaluation criteria beyond the expected net-benefit measure of standard economic BCA. A number of approaches have been suggested that share a link to the idea of a "safe minimum standard" (SMS) first advanced by Ciriacy-Wantrup (1952) and refined by Bishop (1978). Woodward and Bishop (1997, p. 506) state that "According to the SMS, policymakers should focus on avoiding critical levels of resources below which economically irreversible degradation of the resource will take place.” Quoting Ciriacy-Wantrup (1952, pp. 261-262), they continue with the observation that "the economic rationale for adopting a safe minimum standard defined in physical terms is allowance for uncertainty" (emphasis added). They argue that an SMS approach is entirely consistent with rational choice if there is significant and difficult-to-quantify uncertainty.

Norton and Toman (1997, p. 562), again quoting Ciriacy-Wantrup, state that "This criterion places a larger burden of proof on those who would destroy important ecosystem functions by asserting that the resource be saved "provided the social costs are bearable..." This rule requires those who would undertake such a risk to a resource to show the costs of protecting it are unacceptably high before undertaking the risk. It is a concrete expression of a moral judgment that 
large-scale negative environmental effects may have unacceptable consequences for the intergenerational distribution of opportunities and well-being." Importantly, the SMS concept explicitly does not require the establishment of fixed, immutable targets without balancing costs and benefits. However, the burden of proof in evaluation of costs and benefits shifts (to a degree dependent on the circumstances) toward protecting the resources in question.

Norton and Toman (1997) and Toman (1999) build on these observations to conceptualize a "two-tier" model for evaluating ecosystem values and risks. In this model, society establishes higher-level rules for determining when environmental impact assessment and economic BCA can be used to inform decisions, and when a broader and more pluralistic approach to evaluation and policy dialogue is needed. They argue that to properly assess risks and costs requires looking at the natural systems involved across multiple spatial and temporal scales.

What do these observations on the importance of irreversibility and intergenerational equity tell us about what is important to measure for assessing climate change? If there were broad agreement on the composition and scale of "critical natural capital" to be protected, such agreement would tell us a lot about what physical indicators need to be measured to provide a fuller picture of climate change risks and the impacts of potential responses. Unfortunately, such agreement does not exist, although efforts such as that of Ekins et al. (2003) provide valuable insights about what is important to consider. In particular, it is important to provide information about the substitutability of other inputs for natural capital services, as a way of gauging the irreversibility and significance of climate change impacts. As noted, this means consideration of ecosystem functions and climate change impacts at various spatial as well as temporal scales. Ultimately, information about the proximity of important ecosystem functions to highly adverse "tipping points" would be especially useful. In a safe-minimum-standard approach, the cost of preventing further ecosystem degradation matters as well.

\section{Perceptions of climate change uncertainty and evaluation of response options}

Dealing with uncertainty is an important element of good practice in standard BCA. Mathematically, when marginal cost is increasing (i.e., total cost is convex), the expected value of cost evaluated across different uncertain states of the world is larger than the cost of the expected value of those states (i.e., 
the certainty-equivalent). If the cost in question is the cost of climate change damages, then this simple argument implies that all else being equal, BCA that fully accounts for climate change uncertainty will imply more aggressive mitigation (and adaptation) activity than a deterministic analysis that uses expected values of climate change impacts. Risk aversion with respect to uncertain future climate change impacts strengthens this conclusion, as does the economics of irreversibility when less aggressive mitigation causes potentially valuable options to be foreclosed. Another factor arguing for more aggressive early mitigation is the possibility of a larger-scale future catastrophe from climate change whose probability of occurrence rises as greenhouse gases accumulate. ${ }^{10}$ On the other hand, mitigation costs are uncertain as well, and early commitment to a mitigation strategy involving irreversible investment also forecloses options (the possibility to use more effective or cheaper mitigation technologies that emerge in the future from current research and development).

Dealing with these complications is not easy, but it can be done and in fact is being done in some studies of long-term climate change impacts and the benefits of mitigation. A bigger challenge for dealing with uncertainty in assessment of climate change impacts and response options is identified in behavioral economics research on how individuals perceive and respond to low-probability, highimpact events. Large-scale catastrophic events of interest would include major sea level rise from melting and collapse of Antarctic or Greenland ice sheets, largescale ecosystem degradation (e.g., the drying out and burning of vast areas of the Amazon forest), or release of methane currently trapped in permafrost and under water that would create a runaway positive feedback loop in terms of warming (see, e.g., Lenton \& Ciscar, 2013). As pointed out, for example, by Pindyck (2013), the way in which these risks are addressed is a key element in determining the logic and soundness of climate policy. However, many low-probability, high-consequence impacts of climate change involve difficult-to-quantify uncertainty.

As noted, a key finding of behavioral research is that individuals tend to weight losses more heavily than equivalent gains. They may also be concerned with ex post regret: how far away an actual policy outcome may be from the ex ante expectation. In addition, individuals tend to anchor their judgments in the status quo, thus implying greater resistance to the relative certainty of near-term mitigation costs over the uncertainty of long-term risk reduction than might be predicted by a standard expected-gains model. Individuals may fix attention more on the consequences of a dreaded event than on its perceived likelihood, so they may see actions that only reduce (but do not eliminate) the probability of

10 See, e.g., Kopits, Marten, and Wolverton (2013), and Van der Ploeg and de Zeeuw (2014). 
such an event as not that useful. Individuals may give more weight to unfamiliar and potentially large-scale hazards than to more familiar and serious hazards, thus implying less resistance to a strong mitigation response (although that resistance would also depend on how uncertainties associated with mitigation activities were viewed). ${ }^{11}$

What do these observations on the uncertainty regarding how individuals respond to uncertainty tell us about what is important to measure for assessing climate change? One implication is that it may be quite difficult to describe a stable and generalizable measure of willingness to pay for reducing the risks of climate change if individuals make choices in ways that are quite distinct from the predictions of standard expected-utility theory. Individuals may respond to new information about climate change by altering the ways they frame and anchor concerns about it. Differences in perception of climate change uncertainty across individuals can pose significant challenges to the standard construct of a representative economic agent. Studies of preference elicitation (by, e.g., Howarth and Wilson (2006) and Spash (2008)), show that provision of information and communication among respondents can significantly affect values expressed.12

It is unclear how different perspectives on the deep uncertainties surrounding climate change could be resolved any time soon. ${ }^{13}$ However, the nature of challenges with respect to understanding how individuals perceive and respond to climate change uncertainty also points toward some ways to try to organize the information gathered and analysis performed. Starting with the observation that individuals confront deep uncertainty with respect to climate change and may exhibit elements of ex post regret, analytical approaches that seek to quantify and minimize potential regret can be as informative as an expected net benefits analysis based on extremely speculative subjective probabilities (Kunreuther

11 For further discussion see e.g., Summers and Zeckhauser (2008), and Berger, Brown, Kousky and Zeckhauser (2011).

12 Sagoff (2004) argues that democratic processes for obtaining expressions of beliefs and desires is the appropriate way to deal with such social questions, and that technocratic BCA has little place in this. An alternative view is to see society as delegating to elected and/or appointed leaders the task of addressing climate change (and other wicked problems) in as rational a way as possible for society as a whole, including the practice of a kind of benevolent paternalism with respect to individual preferences that are subject to logical paradoxes (e.g., intransitivity, nonmonotonicity) or misperception of risks (Zeckhauser \& Sunstein, 2009).

13 Given that individuals may be little affected by whether the risk of a climate change catastrophe has a probability of $1 \%$ or $0.1 \%$ (see, e.g., Summers \& Zeckhauser, 2008), there is some reason to doubt how much even significant scientific progress in narrowing climate change uncertainties might affect individuals' beliefs and preferences over what to do about the risk of climate change catastrophe. 
et al., 2013; Lempert, Groves, Popper, \& Bankes, 2006). The key is the space over which potential regret is defined and assessed. In particular, it is important to consider regret over how a policy performed relative to expectations in mitigating greenhouse gases or strengthening resilience to climate change, regret over divergence between anticipated and actual cost of implementation, and regret over side effects (more negative or less positive than anticipated).

Since individuals facing deep uncertainties have limited capabilities to "price” different aspects of climate change risks, there is also a case for using a multi-criteria approach. Kousky, Rostapshova, Toman and Zeckhauser (2009) illustrate this approach for assessing different policy responses to lessen the potential for a global-scale climatic catastrophe. They evaluate radical energy sector decarbonization, dramatic land use changes for lowering exposure to risks, and injection of particulates into the atmosphere to prevent warming (a form of so-called "radiation management"), using four criteria: technical efficacy, cost, robustness, and flexibility. Bellamy, Chilvers, Vaughan and Lenton (2013) evaluate a number of general responses to climate change (mitigation and adaptation) against several criteria including economic, efficacy in limiting climatic change, other environmental impacts, ethical issues, technical feasibility, and political and social aspects. Better understanding which of these criteria are more relevant than others for assessing public perceptions of climate change risks and response options can provide information on what types of scientific and technological information may be most useful.

\section{Conclusions}

Economic analysis remains a key part of the effort to assess climate change risks and response options, even after one recognizes that conventional BCA has important limitations in addressing these issues. Nevertheless, differences in ecological value metrics, the importance of addressing intergenerational impacts and critical natural capital considerations in the face of irreversibility, and the existence of deep uncertainty surrounding climate change point to the value of having several types of information for assessing climate change.

This paper has focused on additional types of information that can help provide a more complete information base for assessing climate change risks and response options. It is important to note first that our current capacity for policy evaluation remains limited. We can measure the atmospheric concentration of greenhouse gases in the atmosphere (although even that measurement depends on a set of judgments about the $\mathrm{CO}_{2}$-equivalency of other greenhouse 
gases). We can estimate the rate of greenhouse gas emissions coming from various sources. We can also measure (with varying degrees of precision) other statistics relevant to the changing climate, such as the areal extent of glaciers and forests, or changes in ocean temperature, salinity, and acidity. While various sorts of physical measurements could be used as proxy indicators for the state of natural capital relevant to the global climate system, translating such physical indicators into measures that relate more clearly to potential future human wellbeing (e.g., changes in agricultural yields, frequency of extreme weather events, or survival probabilities for iconic species) depends on a variety of assumptions about various factors subject to considerable uncertainty. We do not escape the problem of uncertainty or the need for making difficult value-related judgments by shifting from economic to physical indicators.

One implication of the discussion in this paper is that improved information about the scale and irreversibility of climate change impacts can be especially useful. Large and irreversible impacts tend to be ones for which monetization of costs is most difficult, uncertainty is the greatest, and the more precautionary approach of a safe minimum standard is most relevant..$^{14}$

Information is needed in particular about the speed of climate change, as well as the magnitude. This information is useful for gauging risks faced by hard-tovalue ecosystem services, and ecosystems that may irreversibly convert to a fundamentally different state. NOAA's climate information website is an example of a source that provides a variety of such information. ${ }^{15}$ Better understanding also is needed as well about the nature of ecosystem vulnerabilities from climate change at a systemic scale, and the consequences of those vulnerabilities for human wellbeing. This kind of information provides a capacity for making more informed judgments about resource substitutability, vis-à-vis "critical natural capital."

14 One approach to economic analysis in this context involves evaluating the potential cost of achieving different degrees of slowdown in the accumulation of greenhouse gases in the atmosphere, and then making informed judgments - based on a range of different types of information about comparative risks - about what levels of climate change risks are acceptable compared with the costs, as best as they can be understood. This approach reflects the idea of CiriacyWantrup mentioned previously, that social costs of protection should be "bearable." It does not rely on the untenable assumption of lexicographic societal interests, with reduction of climate change risks coming first and costs of risk reduction second. Nor does it attempt to summarize the nature of climate change risks with a few numbers on the marginal (discounted presentvalue) cost of greenhouse gas emission accumulation.

15 See http://www.climate.gov/\#understandingClimate. The acceleration of climate change is often noted as an indication of why there is need for greater concern. On the other hand, recent research has begun to shed light on how a slowing down of certain processes may be a harbinger of an approaching tipping point (Lenton, 2011; Scheffer et al., 2012). 
Similarly, information is needed about the flexibility and robustness of potential policy responses as well as their expected benefits and costs. These are areas where research needs to advance considerably to provide the information desired.

To make well-informed judgments about climate change risks and policy responses also requires better understanding how the public perceives climate change risks, and how those risks compare with other policy-relevant risks. In general terms, the public's attitude toward risk can substantially influence the social cost of carbon (see, e.g., Anthoff, Tol, \& Yohe, 2009). However, as noted in Section 4, there are reasons why individuals may systematically overstate or understate the significance of climate change risks, for example, because probabilities are misconstrued or impacts are outside the realm of experience. ${ }^{16}$ Thus, information about how society evaluates other risks (e.g., expenditures on reducing risks of other causes of ecological degradation and losses from extreme events) can complement information on climate change risks themselves and public attitudes toward them in establishing comparative risk valuations for use in policy evaluation.

One final point involves the level of aggregation to use in combining various types of information. For example, Bellamy et al. (2013) aggregate the evaluations of their various policy options across their multiple criteria to come up with overall composite scores. This kind of aggregation is very familiar in working with economic data, where relative (actual, adjusted, or shadow) prices provide the necessary weights. It is also used in other contexts.

Böhringer and Jochem (2007) provide a wide-ranging critique of both economic and non-economic indicators for sustainability that has relevance for this discussion as well. They argue that the indicators they review do not adequately represent all the facets of sustainability, and that there are no generally accepted ways to normalize or weight different metrics to form an indicator. Aggregation inherently involves value judgments that can be easily lost once the aggregated indicator is made the focus of attention, involving weights that are open to criticism in terms of their implications for human values. ${ }^{17}$ It seems better to retain the original information collected so that the relevance and adequacy of specific metrics for assessing climate change can be judged and debated.

Acknowledgments: Views expressed in the paper are the author's alone and should not be attributed to the World Bank or its member countries. The author acknowledges with gratitude comments from Fran Sussman, Ed Barbier, an

16 This is different than "dread" of an unfamiliar risk, which is a reflection of preferences. 17 Ravallion (2010) makes this point in his critique of "mash-up" indicators of economic development. 
anonymous referee, and other authors in the issue, as well as editorial assistance from Elaine Wylie.

\section{References}

Anthoff, D., Tol, R. S. J., \& Yohe, G. W. (2009). Risk aversion, time preference, and the social cost of carbon. Environmental Research Letters, 4(2), 024002. doi:10.1088/17489326/4/2/024002.

Batie, S. S. (2008). Wicked problems and applied economics. American Journal of Agricultural Economics, 90(5), 1176-1191.

Bellamy, R., Chilvers, J., Vaughan, N. E., \& Lenton, T. M. (2013). “Opening up” geoengineering appraisal: Multi-Criteria Mapping of options for tackling climate change. Global Environmental Change, 23(5), 926-937. doi:10.1016/j.gloenvcha.2013.07.011.

Berger, A., Brown, C., Kousky, C., \& Zeckhauser, R. (2011). The challenge of degraded environments: How common biases impair effective policy. Risk Analysis, 31(9), 1423-1433. doi:10.1111/j.1539-6924.2010.01477.x.

Bishop, R. C. (1978). Endangered species and uncertainty: The economics of a safe minimum standard. American Journal of Agricultural Economics, 60(1), 10. doi:10.2307/1240156.

Böhringer, C., \& Jochem, P. E. P. (2007). Measuring the immeasurable: A survey of sustainability indices. Ecological Economics, 63(1), 1-8. doi:10.1016/j.ecolecon.2007.03.008.

Ciriacy-Wantrup, S. V. (1952). Resources conservation: Economics and policies. Berkeley: University of California Press.

Ekins, P., Simon, S., Deutsch, L., Folke, C., \& De Groot, R. (2003). A framework for the practical application of the concepts of critical natural capital and strong sustainability. Ecological Economics, 44(2-3), 165-185.

Fankhauser, S., Tol, R. S. J., \& Pearce, D. W. (1997). The aggregation of climate change damages: A welfare theoretic approach. Environmental and Resource Economics, 10(3), 249-266. doi:10.1023/A:1026420425961.

Fankhauser, S., Tol, R. S. J., \& Pearce, D. W. (1998). Extensions and alternatives to climate change impact valuation: On the critique of IPCC Working Group III's impact estimates. Environment and Development Economics, 3(01), 59-81. doi:10.1017/ S1355770X98000047.

Faucheux, S., \& Froger, G. (1995). Decision-making under environmental uncertainty. Ecological Economics, 15(1), 29-42. doi:10.1016/0921-8009(95)00018-5.

Gerst, M. D., Howarth, R. B., \& Borsuk, M. E. (2010). Accounting for the risk of extreme outcomes in an integrated assessment of climate change. Energy Policy, 38(8), 4540-4548. doi:10.1016/j.enpol.2010.04.008.

Gowdy, J. (2004). The revolution in welfare economics and its implications for environmental valuation and policy. Land Economics, 80(2), 239-257.

Gowdy, J., \& Manner, M. (2010). The evolution of social and moral behavior: Evolutionary insights for public policy. Ecological Economics, 69(4), 753-761. doi:10.1016/j. ecolecon.2008.04.021.

Gsottbauer, E., \& Bergh, J. C. J. M. van den. (2011). Environmental policy theory given bounded rationality and other-regarding preferences. Environmental and Resource Economics, 49(2), 263-304. doi:10.1007/s10640-010-9433-y. 
Hammitt, J. K. (2013). Positive versus normative justifications for benefit-cost analysis: Implications for interpretation and policy. Review of Environmental Economics and Policy, 7(2), 199-218. doi:10.1093/reep/ret009.

Hanley, N., \& Barbier E. B. (2009). Pricing Nature: Cost-Benefit Analysis and Environmental Policy. Cheltenham, UK: Edward Elgar.

Howarth, R. B. (1997). Sustainability as opportunity. Land Economics, 73(4), 569. doi:10.2307/3147246.

Howarth, R. B. (2007). Towards an operational sustainability criterion. Ecological Economics, 63(4), 656-663. doi:10.1016/j.ecolecon.2007.02.009.

Howarth, R. B., \& Wilson, M. A. (2006). A theoretical approach to deliberative valuation: Aggregation by mutual consent. Land Economics, 82(1), 1-16.

IPCC. (2007). Climate change 2007: Synthesis report. Contribution of Working Groups I, II and III to the Fourth Assessment Report of the Intergovernmental Panel on Climate Change (p. 104). Geneva, CH: IPCC.

IPCC. (2014). Summary for policymakers, in Climate Change 2014: Impacts, Adaptation, and Vulnerability. Part A: Global and Sectoral Aspects. Contribution of Working Group II to the Fifth Assessment Report of the Intergovernmental Panel on Climate Change. Cambridge, UK and New York: Cambridge University Press: 1-32.

Knight, F. H. (1921). Risk, uncertainty, and profit. Library of Economics and Liberty. Retrieved from http://www.econlib.org/library/Knight/knRUP.html.

Kopits, E., Marten, A. L., \& Wolverton, A. (2013). Moving forward with incorporating "catastrophic" climate change into policy analysis (Working Paper \#2013-01). Washington, DC:." National Center for Environment Economics. Retrieved from http://yosemite.epa. gov/ee/epa/eed.nsf/WPNumber/2013-01?OpenDocument.

Kousky, C., Rostapshova, O., Toman, M., \& Zeckhauser, R. (2009). Responding to threats of climate change mega-catastrophes. Washington, DC: The World Bank. Retrieved from http://elibrary.worldbank.org/doi/book/10.1596/1813-9450-5127.

Kunreuther, H., Heal, G., Allen, M., Edenhofer, O., Field, C. B., \& Yohe, G. (2013). Risk management and climate change. Nature Climate Change, 3(5), 447-450. doi:10.1038/ nclimate1740.

Lempert, R. J., Groves, D. G., Popper, S. W., \& Bankes, S. C. (2006). A general, analytic method for generating robust strategies and narrative scenarios. Management Science, 52(4), 514-528. doi:10.1287/mnsc.1050.0472.

Lenton, T. M. (2011). Early warning of climate tipping points. Nature Climate Change, 1(4), 201-209. doi:10.1038/nclimate1143.

Lenton, T. M., \& Ciscar, J.-C. (2013). Integrating tipping points into climate impact assessments. Climatic Change, 117(3), 585-597. doi:10.1007/s10584-012-0572-8.

Leopold, A. (1949). A Sand County almanac, and sketches here and there. Oxford, UK: Oxford University Press.

Masood, E. (1995). Developing countries dispute use of figures on climate change impacts. Nature, 376(6539), 374.

Nelson, J. A. (2013). Ethics and the economist: What climate change demands of us. Ecological Economics, 85, 145-154.

Neumann, J. E, \& Strzepek, K. (2014). State of the literature on the economic impacts of climate change in the United States. Journal of Benefit-Cost Analysis, 5(3), 411-443.

Norton, B. G. (2005). Sustainability: A philosophy of adaptive ecosystem management. Chicago, IL: University Of Chicago Press. 
Norton, B. G., \& Noonan, D. S. (2007). Ecology and valuation: Big changes needed. Ecological Economics, 63, 664-675.

Norton, B. G., \& Toman, M. A. (1997). Sustainability: ecological and economic perspectives. Land Economics, 73(4), 553. doi:10.2307/3147245.

Pearce, D. W., Cline, W. R., Achanta, A. N., Fankhauser, S., Pachauri, R. K., Tol, R. S. J., \& Vellinga, P. (1996). The social costs of climate change: Greenhouse damage and the benefits of control. In J. P. Bruce, H. Lee \& E. F. Haites (Eds.), Climate Change 1995: Economic and Social Dimensions of Climate Change. Contribution of Working Group III to the Second Assessment Report of the Intergovernmental Panel on Climate Change. Cambridge, UK: Cambridge University Press.

Pindyck, R. S. (2013). The climate policy dilemma. Review of Environmental Economics and Policy, 7(2), 219-237. doi:10.1093/reep/ret007.

Ravallion, M. (2010). Mashup indices of development. Washington, DC: The World Bank. Retrieved from http://elibrary.worldbank.org/doi/book/10.1596/1813-9450-5432.

Sagoff, M. (2004). Price, principle, and the environment. Cambridge, UK; New York, NY: Cambridge University Press.

Scheffer, M., Carpenter, S. R., Lenton, T. M., Bascompte, J., Brock, W., Dakos, V., \& Vandermeer, J. (2012). Anticipating critical transitions. Science, 338(6105), 344-348. doi:10.1126/ science.1225244.

Spash, C. L. (2008). Deliberative monetary valuation and the evidence for a new value theory. Land Economics, 84(3), 469-488. doi:10.3368/le.84.3.469.

Summers, L., \& Zeckhauser, R. (2008). Policymaking for posterity. Springer Science and Business Media, 37, 115-140.

Sussman, F., Weaver, C., \& Grambsch, (2014). Challenges in applying the paradigm of welfare economics to climate change. Journal of Benefit-Cost Analysis, 5(3), 347-376.

Toman, M. A. (1994). Economics and "sustainability": Balancing trade-offs and imperatives. Land Economics, 70(4), 399-413.

Toman, M. A. (1999). Sustainable decision making: The state of the art. In M. O'Connor \& C. Spash (Eds.), In Valuation and the Environment: Principles and Practices. Cheltenham, UK: Edward Elgar Publishing, Ltd.

U.S. EPA. (2014). Guidelines for preparing economic analyses. U.S. Environmental Protection Agency. Retrieved from http://yosemite.epa.gov/ee/epa/eerm.nsf/vwAN/EE-0568-50. pdf/\$file/EE-0568-50.pdf.

U.S. Office of Management and Budget (OMB). (2003). Circular A-4. Washington, DC: OMB. Retrieved from http://www.whitehouse.gov/omb/circulars_a004_a-4.

Van der Ploeg, F., \& de Zeeuw, A. (2014). Climate tipping and economic growth: Precautionary saving and the social cost of carbon. Presented at the Fifth World Congress of Environmental and Resource Economists, Istanbul: Oxford Centre for the Analysis of Resource Rich Economies, University of Oxford.

Weyant, J. (2014). Integrated assessment of climate change: state of the literature. Journal of Benefit-Cost Analysis, 5(3), 377-409.

Woodward, R. T., \& Bishop, R. C. (1997). How to decide when experts disagree: Uncertaintybased choice rules in environmental policy. Land Economics, 73(4), 492-507.

Yohe, G. (2009). Toward an integrated framework derived from a risk-management approach to climate change. Climatic Change, (95), 325-339.

Zeckhauser, R. J., \& Sunstein, C. R. (2009). Overreaction to fearsome risks (Discussion Paper 2009-02). Cambridge, MA: Harvard Environmental Economics Program. 